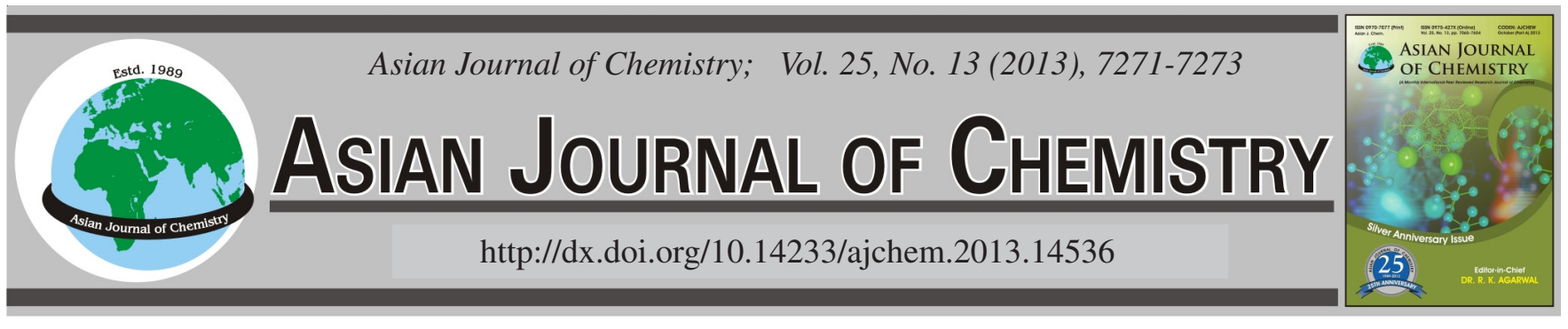

\title{
Synthesis and Antifungal Activity of 2-(4-Chlorophenylcarbamoyl)phenyl Acetate
}

\author{
XiAORONG TANG ${ }^{1, *}$, Hui Feng ${ }^{2}$, Quan Du ${ }^{1}$ and Ling WAng ${ }^{1}$
}

${ }^{1}$ School of Physics and Chemistry, Xihua University, Chengdu 610039, P.R. China

${ }^{2}$ School of Bioengineering, Xihua University, Chengdu 610039, P.R. China

*Corresponding author: Tel: +8628 87720208; E-mail: tangxiaorong0901@163.com

(Received: 7 September 2012;

Accepted: 24 June 2013)

AJC-13688

2-(4-Chlorophenylcarbamoyl)phenyl acetate was synthesized by the ammonolysis of 2-(chlorocarbonyl)phenyl acetate. Its structure was confirmed by IR and ${ }^{1} \mathrm{H}$ NMR. Its antifungal activity against Sclerotinia sclerotiorum and Helminthosprium maydis has been determined in the laboratory. Results showed that it had good antifungal activity against the above two different pathogenic fungi of plants. Its median effective concentrations $\left(\mathrm{EC}_{50}\right.$ ) were $28 \mathrm{mg} \mathrm{L}^{-1}$ and $2.3 \mathrm{mg} \mathrm{L}^{-1}$, respectively.

Key Words: Antifungal activity, 2-(4-Chlorophenylcarbamoyl)phenyl acetate, Synthesis.

\section{INTRODUCTION}

Sclerotinia sclerotiorum is a harmful disease of cole ${ }^{1}$. For a long period, benzimidazole fungicides have been mostly used to control it. In recent years, however, it has developed resistance to the above fungicides ${ }^{2-6}$. Moreover, its scope of resistance continues to expand and has already included many new fungicides ${ }^{7-9}$.

Similarly, Helminthosprium maydis is a pathogenic fungus of plants which has serious harm to maize. Over the past decades, synthetic fungicides including carbendazim have been used to prevent it. Nevertheless, the development of its resistance to all the fungicides has reduced the efficacy of fungicidal treatment ${ }^{10-16}$. Therefore, new fungicides are continually required.

It is well-known that since aspirin (acetylsalicylic acid) was first marketed in 1899 , it has been widely used for the treatment of pains, fever and colds ${ }^{17-29}$. Thus, in the paper, 2-(4-chlorophenylcarbamoyl)phenyl acetate was synthesized based on aspirin. In the meantime, its antifungal activity has been evaluated in the laboratory to find new fungicides with high efficacy and low toxicity.

\section{EXPERIMENTAL}

Sclerotinia sclerotiorum and Helminthosprium maydis were obtained from the Chinese Academy of Agricultural Sciences. They were preserved at $4{ }^{\circ} \mathrm{C}$. All chemicals and solvents were purchased from commercial sources unless specified otherwise. IR spectra were recorded on a Thermofisher Nicolet-6700 spectrophotometer. ${ }^{1}$ H NMR spectra were taken on a Varian Unity Inova-400 instrument using deuteron-chloroform as the solvent.

Synthesis of 2-(4-chlorophenylcarbamoyl)phenyl acetate: The target compound was synthesized according to the reaction shown in Fig. 1. 4-Chloroaniline $(0.02 \mathrm{~mol})$ and pyridine $(0.02 \mathrm{~mol})$ were dissolved in $\mathrm{CH}_{2} \mathrm{Cl}_{2}(15 \mathrm{~mL})$. The mixture was stirred and heated to $35-45^{\circ} \mathrm{C}$. 2-(Chlorocarbonyl)phenyl acetate $(0.02 \mathrm{~mol})$ with $\mathrm{CH}_{2} \mathrm{Cl}_{2}(15 \mathrm{~mL})$ was slowly added to the above mixture under stirring until the reaction was complete. The precipitate was filtered and washed with distilled water. The pure compound was obtained by recrystallization in anhydrous ethanol.

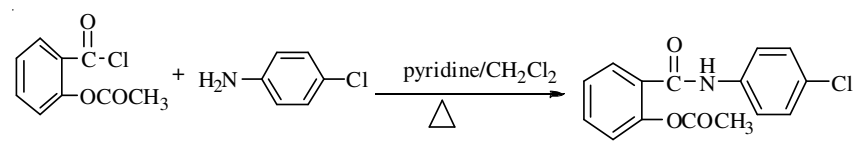

Fig. 1. Synthetic method of 2-(4-chlorophenylcarbamoyl)phenyl acetate

The synthesized compound (m.f. $\mathrm{C}_{15} \mathrm{H}_{12} \mathrm{NO}_{3} \mathrm{Cl}$ ): white needle crystal; yield: $40 \%$; m.p. $133-134{ }^{\circ} \mathrm{C}$; IR(KBr, $v_{\max }$ $\mathrm{cm}^{-1}$ ): 3487, 3285, 3190, 3111, 3048, 1755, 1656, 1608, 1595, 1533, 1493, 1447, 1396, 1317, 1207, 1172, 830, 751, 701, 589; ${ }^{1} \mathrm{H}$ NMR (400 MHz, $\mathrm{CDCl}_{3}$ ) $\delta$ (ppm): $8.10(\mathrm{~s}, 1 \mathrm{H}), 7.80$ (d, $J=7.6 \mathrm{~Hz}, 1 \mathrm{H}), 7.49-7.55(\mathrm{~m}, 3 \mathrm{H}), 7.30-7.36(\mathrm{~m}, 3 \mathrm{H})$, $7.14(\mathrm{~d}, \mathrm{~J}=8.4 \mathrm{~Hz}, 1 \mathrm{H}), 2.31$ (s, 3H).

Assay of antifungal activity: The antifungal activity of the synthesized compound against Sclerotinia sclerotiorum and Helminthosprium maydis was determined using the plate growth rate method ${ }^{30}$. 
TABLE-1

ANTIFUNGAL ACTIVITY OF 2-(4-CHLOROPHENYLCARBAMOYL)PHENYL ACETATE AGAINST Sclerotinia sclerotiorum

\begin{tabular}{|c|c|c|c|c|c|c|c|c|c|c|}
\hline & \multicolumn{5}{|c|}{ 2-(4-Chlorophenylcarbamoyl)phenyl acetate } & \multicolumn{5}{|c|}{ Carbendazim } \\
\hline Concentration $\left(\mathrm{mg} \mathrm{L}^{-1}\right)$ & 100 & 50 & 25 & 12.5 & 6.3 & 50 & 25 & 12.5 & 6.3 & 3.1 \\
\hline Inhibition of growth ${ }^{*}(\%)$ & 93.7 & 79.0 & 37.2 & 17.1 & 6.3 & 94.1 & 85.5 & 74.9 & 61.1 & 49.5 \\
\hline Regressive equation $(Y=a X+b)$ & \multicolumn{5}{|c|}{$Y=2.6821 X+1.1201$} & \multicolumn{5}{|c|}{$Y=1.2683 X+4.3132$} \\
\hline $\mathrm{EC}_{50}\left(\mathrm{mg} \mathrm{L}^{-1}\right)$ & \multicolumn{5}{|c|}{28.0} & \multicolumn{5}{|c|}{3.5} \\
\hline (95\% CL) & \multicolumn{5}{|c|}{$(24.9-31.5)$} & \multicolumn{5}{|c|}{$(2.4-4.6)$} \\
\hline Correlative coefficient $(r)$ & \multicolumn{5}{|c|}{0.9507} & \multicolumn{5}{|c|}{0.9614} \\
\hline$\chi^{2}$ & \multicolumn{5}{|c|}{4.416} & \multicolumn{5}{|c|}{0.605} \\
\hline
\end{tabular}

TABLE-2

ANTIFUNGAL ACTIVITY OF 2-(4-CHLOROPHENYLCARBAMOYL)PHENYL ACETATE AGAINST Helminthosprium maydis

\begin{tabular}{|c|c|c|c|c|c|c|c|c|c|c|}
\hline & \multicolumn{5}{|c|}{ 2-(4-Chlorophenylcarbamoyl)phenyl acetate } & \multicolumn{5}{|c|}{ Carbendazim } \\
\hline Concentration $\left(\mathrm{mg} \mathrm{L}^{-1}\right)$ & 100 & 50 & 25 & 12.5 & 6.3 & 100 & 50 & 25 & 12.5 & 6.3 \\
\hline Inhibition of growth* $(\%)$ & 91.6 & 85.1 & 78.8 & 70.8 & 65.6 & 87.5 & 70.8 & 57.5 & 41.5 & 35.5 \\
\hline Regressive equation $(\mathrm{Y}=\mathrm{aX}+\mathrm{b})$ & \multicolumn{5}{|c|}{$Y=0.7948 X+4.7185$} & \multicolumn{5}{|c|}{$Y=1.2373 X+3.5189$} \\
\hline $\mathrm{EC}_{50}\left(\mathrm{mg} \mathrm{L}^{-1}\right)$ & \multicolumn{5}{|c|}{2.3} & \multicolumn{5}{|c|}{15.7} \\
\hline$(95 \% \mathrm{CL})$ & \multicolumn{5}{|c|}{$(0.5-4.5)$} & \multicolumn{5}{|c|}{$(12.1-19.6)$} \\
\hline Correlative coefficient $(r)$ & \multicolumn{5}{|c|}{0.9698} & \multicolumn{5}{|c|}{0.9808} \\
\hline$\chi^{2}$ & \multicolumn{5}{|c|}{0.472} & \multicolumn{5}{|c|}{2.862} \\
\hline
\end{tabular}

The synthesized compound and carbendazim (purity 90\%) were dissolved in dimethyl sulfoxide, respectively. The two solutions were diluted into five different concentrations with distilled water, respectively. They were added to the sterile culture medium (PDA) at $45^{\circ} \mathrm{C}$, mixed to homogeneity and transferred to sterile Petri dishes to solidify. A mycelium agar disc ( $5 \mathrm{~mm}$ in diameter) of the target fungi was placed in the center of PDA plates. They were incubated at $28^{\circ} \mathrm{C}$ in the dark until the target fungi used as controls covered the surface of these plates. Control groups were treated with the corresponding solutions without the synthesized compound or carbendazim. The experiment for each concentration was replicated three times. The diameter of the fungi in the cultures was measured and the inhibition of growth was calculated according to the formula of Abbott. $\mathrm{EC}_{50}$ values were calculated with the statistics package for the social sciences based on probit analysis.

\section{RESULTS AND DISCUSSION}

The target compound [2-(4-chlorophenylcarbamoyl)phenyl acetate] has been successfully synthesized by means of the ammonolysis of 2-(chlorocarbonyl)phenyl acetate and then its structure has been confirmed by IR and ${ }^{1} \mathrm{H}$ NMR spectra.

Antifungal activity against Sclerotinia sclerotiorum: Compared with the efficient fungicide carbendazim, the synthesized compound was submitted to laboratorial bioassay. The results are presented in Table-1. It had good antifungal activity against Sclerotinia sclerotiorum. Its $\mathrm{EC}_{50}$ value was $28 \mathrm{mg} \mathrm{L}^{-1}$. The results of regressive and correlative analyses indicated that the correlation was significant between concentration and efficacy. Its correlative coefficient was 0.9507 . Chi-square test demonstrated that the results were reliable $\left(\chi^{2}=4.416, \mathrm{df}=3\right.$, $\mathrm{p}>0.05)$.
Antifungal activity against Helminthosprium maydis: As shown in Table-2, using the efficient fungicide carbendazim as the comparative standard, the synthesized compound was subjected to laboratorial bioassay. Its $\mathrm{EC}_{50}$ value reached 2.3 $\mathrm{mg} \mathrm{L}^{-1}$. The results of regressive and correlative analyses revealed that the correlation was significant between concentration and efficacy. The correlative coefficient was 0.9698 . As for the results of Sclerotinia sclerotiorum, chi-square test also showed that the results were reliable $\left(\chi^{2}=0.472, \mathrm{df}=3\right.$, $\mathrm{p}>0.05)$.

\section{Conclusion}

The results of laboratory bioassay have apparently shown that though the antifungal activity of 2-(4-chlorophenylcarbamoyl)phenyl acetate against Sclerotinia sclerotiorum was inferior to carbendazim, its antifungal activity against Helminthosprium maydis was superior to carbendazim. Therefore, the structural modification of aspirin was very successful. In addition, the structure of the obtained compound is simple and its chemical synthesis is easy. Thus, based on it, more derivatives may be further synthesized so as to survey quantitative structure-activity relationships and find new fungicides with high efficacy and low toxicity as well as safety to nontarget organisms. On the other hand, the compound is also promising in the agricultural chemistry field because it had good antifungal activity against the two different pathogenic fungi of plants.

\section{ACKNOWLEDGEMENTS}

This project was supported by the Scientific Research Fund of Sichuan Provincial Education Department (No. 09ZA113), the Key Scientific Research Fund of Xihua University (No. Z0913302) and the Organic Chemistry Key Discipline of Xihua University. 


\section{REFERENCES}

1. X.J. Chen, M.J. Cao, Y. Wang, Y.H. Tong and J.Y. Xu, Chin. J. Oil Crop Sci., 31, 503 (2009).

2. Y.L. Pan, Z.Y. Wang and H.Z. Wu, J. Jiangsu Agric., 13, 32 (1997).

3. Z.Q. Shi, M.G. Zhou and Z.Y. Ye, J. Jiangsu Agric., 16, 212 (2000).

4. W. Li, Y.J. Zhou and H.G. Chen, Chin. J. Oil Crop. Sci., 29, 63 (2007).

5. K.Y. Liu and F.X. Chen, Anhui Agric. Sci., 35, 756 (2007).

6. R.E. Beever and H.M.R. Brien, Agric. Res., 26, 391 (1983).

7. D.G. Hutton, Australasian Plant Pathol., 17, 34 (1988).

8. Y.X. Qi, F.X. Chen and K.J. Ding, Pesticides, 8, 567 (2006).

9. FAO, Plant Protect. Bull., 30, 30 (1982).

10. A. Have, R. van Berloo, P. Lindhout and J.A.L. van Kan, Eur. J. Plant Pathol., 113, 153 (2007)

11. S.I. Ignatova, N.S. Gorshkova and T.A. Tereshonkova, Acta Physiol. Plant, 22, 326 (2000).

12. H. Egashira, A. Kuwashima, H. Ishiguro, K. Fukushima, T. Kaya and S. Imanishi, Acta Physiol. Plant, 22, 324 (2000).

13. R.L. Guimaraes, R.T. Chetelat and H.U. Stotz, Eur. J. Plant Pathol., 110, 13 (2004).

14. R. Finkers, P. van de Berg, R. van Berloo, A. Have, A.W. van Heusden, J.A.L. van Kan and P. Lindhout, Theor. Appl. Genet., 114, 585 (2007).
15. R. Finkers, Y.L. Bai, P. van de Berg, R. van Berloo, A. Have, J.A.L. van Kan, P. Lindhout and A.W. van Heusden, Theor. Appl. Genet., 114, 1071 (2007).

16. R. Finkers, Y.L. Bai, P. van de Berg, R. van Berloo, A. Have, J.A.L. van Kan, P. Lindhout and A.W. van Heusden, Euphytica, 159, 83 (2008).

17. X. Wang, Med. Hypotheses, 50, 239 (1998).

18. D.W. Gilroy, Prostaglandins Leukot. Essent. Fatty Acids, 73, 203 (2005).

19. C. Millikan and N. Futrell, J. Stroke Cerebrovasc. Dis., 5, 248 (1995).

20. J.R. Vane, R.J. Flower and R.M. Botting, Stroke, 21, 12 (1990).

21. M.L. Dyken, H.J.M. Barnett and J.D. Easton, Stroke, 23, 1395 (1992).

22. H. Tohgi, S. Konno and K. Tamura, Stroke, 23, 1400 (1992).

23. R.H. Ackerman and K.L. Newman, Ann. Neurol., 28, 224 (1990).

24. C.M. Helgason, K.L. Tortorice and S.R. Winkler, Stroke, 24, 345 (1993).

25. W.K. Hoss, J.D. Easton and H.P. Adams, N. Engl. J. Med., 321, 501 (1989).

26. D.M. McCarthy, Best Pract. Res. Clin. Gastroenterol., 26, 101 (2012).

27. R. Eccles, Int. Pharm. J., 6, 7 (1995).

28. C. Lampl, M. Voelker and H.C. Diener, J. Neurol., 254, 705 (2007).

29. J.A. Forbes, I.A. Edquist and F.G. Smith, Pharmacotherapy, 11, 64 (1991).

30. W. Huang and G.F. Yang, Bioorg. Med. Chem., 14, 8280 (2006). 